\title{
Sustainable Transport in Upper Austria - Case Study for Setting up a Living Lab Concept to Accelerate Innovations
}

\author{
Christian Haider ${ }^{1 *}$, Ursula Kopp ${ }^{1}$, Markus Pajones ${ }^{1}$
}

\begin{abstract}
The research team is currently working on defining a suitable path towards the design and implementation of a Living Lab for developing, testing and demonstrating innovations in sustainable transport operations. There are several examples that focus on transport and mobility, either addressing individual or freight transport. The combination of both topics is seen as a unique chance to find new ways for a sustainable transport system and mobility behavior. The region of Upper Austria is used as a research case in order to demonstrate results and findings of an applied research project, called "Mobility Lab Upper Austria."
\end{abstract}

Keywords: Living Lab; sustainable transport; stakeholder integration;

Submitted: $\quad$ August 25th 2016 / Approved: September 12th 2016

\section{Introduction}

Within the following paper, a geographic focus will be laid on the region of Upper Austria, based on its strongly shaped industrial structure. Between 2001 and 2012, a general increase in the use of motorized private transport and a decrease in the use of environmentally friendly transportation (e.g. bikes, pedestrians, and public transport) has been noted. As a result, the high rate of individual motorists is forcing companies to spend sufficient resources in order to provide appropriate facilities (mainly parking) for commuters. Out of 195,900 trips to Linz (capital of Upper Austria), 140,500 are made with the use of private vehicles. ${ }^{1}$ The industry is therefore particularly responsible for motorized passenger and freight traffic. Hence, the paper focuses on the term "industrial mobility." This addresses those traffic streams that are mainly induced by economic activity, such as commuter traffic, business trips, customer and visitor traffic. Mobility of goods mainly includes supply, production and distribution transport as well as waste disposal. Those research fields are supplemented by transition-oriented approaches, allowing them to work in comprehensive focal areas, such as energy, communication and information technology, and social innovation.
Figure 1: Characteristics of the term "industrial mobility."

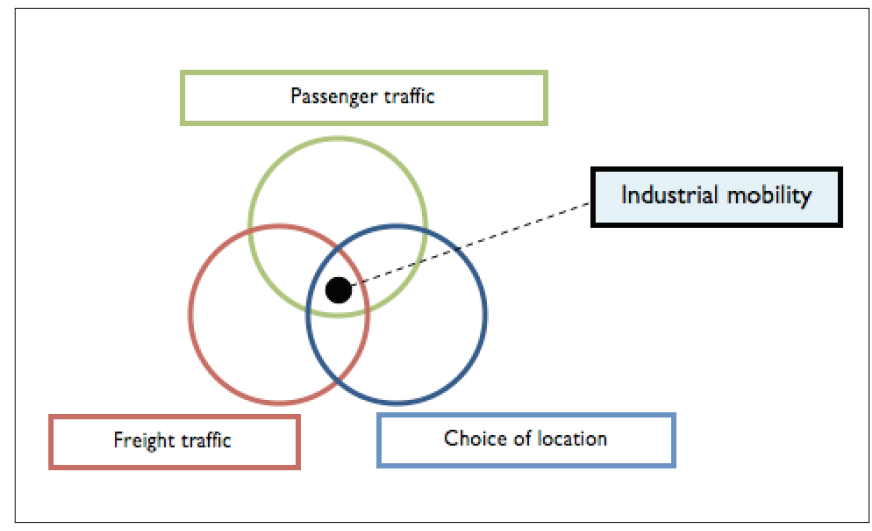

Industrial mobility can be explained by the company's need to produce goods, including the distribution afterwards. This is implemented by freight traffic. Freight traffic can be undertaken using different kinds of transport modes and vehicles. The more alternatives a company has to transport their goods, the greater is the mobility level of the company. Industrial mobility also includes the individual mobility of employees. This traffic takes place within different forms, e.g. individual and public transport, with a bike or by walking. Again, the more alternatives a person has to get to and from the company, the greater is the personal mobility level. The overall mobility level of a company also depends on the impact factors of the surrounding area and the included infrastructure.

University of Applied Sciences Upper Austria, Logistikum Steyr, Austria

*Corresponding author: christian.haider@fh-steyr.at

(1) Traffic survey done by the federal province of Upper Austria (available here: https://www.land-oberoesterreich.gv.at/23652.htm). 
The development of a Living Lab concept allows for the inclusion of perceptions, perspectives and values of the actors involved in the industrial mobility sector. Hence, the research team analyzes research structures that support the creation of innovative solutions within the transportation and mobility sector in Upper Austria. The aim of this paper is therefore the demonstration of a conceptual Living Lab path that can facilitate value-driven and democratized innovation.

In this paper we will first describe the general theoretical idea of Living Labs based on a literature review. Subsequently we indicate the methodology of the project that we use as a case study, exploring and explaining the model for setting up a Living Lab concept from an applied point of view. We illustrate the contextual components of each single step within the implementation path with the case study project material and conclude with a reflection of its use for future activities.

\section{Theory - Living Lab}

A Living Lab setting should enable a "new way of thinking" to understand and manage the complex issues within defining sustainable transport solutions. Therefore, it is central to differentiate the use of the term 'laboratory' in this paper with the classical use of the term. Conventionally, the term 'laboratory' refers to an area or a place where researchers and scientists carry out specific experiments (e.g. chemistry, soil analysis) ( (Nguyen, Bosch, \& Maani, 2011). The authors of this paper define a Living Lab as a real-life test and experimentation environment where users and producers co-create innovations, often operating in a territorial context (e.g. city, region) (Veeckman, Schuurman, Leminen, \& Westerlund, 2013). The purpose of such a laboratory is to enable different stakeholders to experiment, test their mental models (assumptions, values, understandings) and to anticipate the consequences of their actions, policies and strategies (Maani, \& Cavana, 2007).

For a common definition of Living Labs, we use the official statements from the European Network of Living Labs (ENoLL). ENoLL is the international federation of benchmarked Living Labs in Europe and worldwide.

A Living Lab is a real-life test and experimentation environment where users and producers co-create innovations. Living Labs have been characterized by the European Commission as Public-Private-People Partnerships (PPPP) for userdriven open innovation. (ENoLL, 2006)

\section{Conceptual Frame and Case Study Method}

The harmonization cube (Mulder, Velthausz, \& Kriens, 2008) serves as groundwork on which the single implementation parts for Living Labs will be conceptualized. The cube represents the most important perspectives of a Living Lab. It describes the following six views upon a Living Lab to communicate the essentials:
- User involvement focuses on co-creation with final consumers (prosumer)

- Service creation focuses on the process of developing new ideas and testing these in a real-world setting

- Infrastructure focuses on the technologies required to perform measurements and analyze collected data

- Governance focuses on the organization of the Living Lab

- Innovation Outcomes focus on the results produced in the Lab - knowledge, products and services

- Methods \& tools show how to acquire the data

Due to the exploratory nature of this paper, the authors employed a qualitative research approach. Case studies have close cooperation with practitioners, which is also the case when dealing with multistakeholder approaches (Gibbert, Ruigrok, Wicki, 2008). The authors of the article restructured this frame to show how Living Lab parts need to be focused.

\section{Results}

\section{Part 1) Living Lab - strategic orientation}

First, a strategic orientation (harmonization cube "governance") needs to be defined in order to evaluate the concrete conditions of a specific region.

- Who are the stakeholders for the definition of future challenges in the central region of Upper Austria within the thematic field of industrial mobility?

The "industrial mobility" approach discussed above, however, has been developed primarily based on researchers' perspectives and understanding of the term in question. In order to validate the need for the topic it was essential to involve relevant stakeholders in a confirmation process to help refine the approach and to identify key topics addressed within the Living Lab setting. Therefore, a joint expert workshop was conducted in Linz (capital region of Upper Austria) to unravel the regional scoping and propose strategies to address the identified issues concerning sustainable transport operations. Workshop participants came from government and private sectors (industry), academic institutions (including research institutions) and representatives from logistics/mobility service providers in Austria. Alongside to this expert discussion, face-to-face meetings were also conducted as they provide a good atmosphere for additional insights. In the "Mobility Lab Upper Austria" the involvement of stakeholders has a number of purposes and goals defined by the research team. First of all, the common purposes are to (i) create better and faster ideas through various inputs and (ii) to create solutions that are better accepted, 
as they have been developed by taking into consideration all the relevant stakeholders' views. But, in addition, the proposed "Mobility Lab Upper Austria" also places emphasis on (iii) fostering societal dialogue, as issues of industrial mobility are directly linked to different other societal challenges, thus (iv) empowering various societal groups by involving them. Another purpose lies in (v) educating people, by offering experience with the innovation methods used thus supporting an innovation culture, and by learning about industrial mobility topics in another form that usually taught in schools/universities.

1. Government on national and regional level (e.g. Land OÖ, The City of Linz

3. Industries (e.g. chemical industry)

5. Providers in the logistics and automotive sector

7. R\&D units and experts

9. Related organizers (e.g. other innovation labs/platforms, clusters, museums, etc.)

11. Public

The stakeholder groups one to six seem equally important for the long-term performance of the "Mobility Lab Upper Austria," as they will play an important role in implementing solutions, but each of them can also be a promoter of a particular topic within the lab. The strategies used to involve them are keeping regular personal contact, showing them the concrete benefits of their work and developing a common strategy within a vision and mission statement. The group R\&D units and experts play a slightly different role. Their typical role of delivering solutions mainly in the form of studies could be enriched by involving them in the development of existing topics, in creating ideas and in developing and testing prototypes. They will also be involved through regular personal contact. The media (8) can act as important multipliers of the "Mobility Lab Upper Austria" - in particular towards the stakeholder groups 9, 10, and 11 - and will be involved at an early stage and through regular information and participation. Related organizers (9) and educational organizations (10) refer to organizations that organize either innovation activities or educational activities in the field. The either or information seems particularly important in order to differentiate what they offer, but also to act as vice versa multipliers and to exchange participants. The involvement of the broad public (11) is considered as a one main characteristic of a Living Lab. The "Mobility Lab Upper Austria" will be open to the public. But, in addition to that, particular groups within the public, which are closely related to the main topic of the lab, will
In order to detect the relevant stakeholders for the "Mobility Lab Upper Austria" an intense stakeholder analysis was carried out. Around 220 stakeholder organizations or groups were analyzed according to their (i) possible contributions to the project, (ii) their interest in the project, (iii) their power to support and influence it, and (iv) their involvement to date. The analysis showed that the following stakeholder groups are most relevant for the "Mobility Lab Upper Austria":

4. Small and Medium-Sized Companies

6. Service providers on behalf of governmental organizations

8. Media

10. Educational organizations (e.g. schools, universities)

be focused on when inviting them to activities: employees, commuters using transportation to get from and to work, drivers of trucks, drivers of public transport, individual drivers.

The governance part of the harmonization cube also stresses the business model perspective. As the Living Lab research highlights this aspect as being one of the missing links for keeping a Living Lab alive (Mastelic, Sahakian, Bonazzi, 2014), the research team deals with this perspective in the section that follows.

\section{Part 2) Living Lab - business model perspective}

Recent studies on the coordination of and cooperation within Living Labs have shown that there are several types and subtypes possible concerning the driving actors, the aims, the main financial contributors as well as the innovation and cooperation approaches. Leminen, Westerlund, and Nyström (2012) introduced four main types of Living Labs according to the driving actors. Another study by the Alcotra Innovation Project (2011) recognized six typical Living Lab profiles by analyzing all Living Labs of the first wave of ENoLL in 2007/2008. Later, Leminen (2013) added to his four-type model the underlying innovation mechanisms. Those three studies together provide a comprehensive model of the types and subtypes of Living Labs as shown in the following table. 
Table 1: Types and subtypes of Living Labs

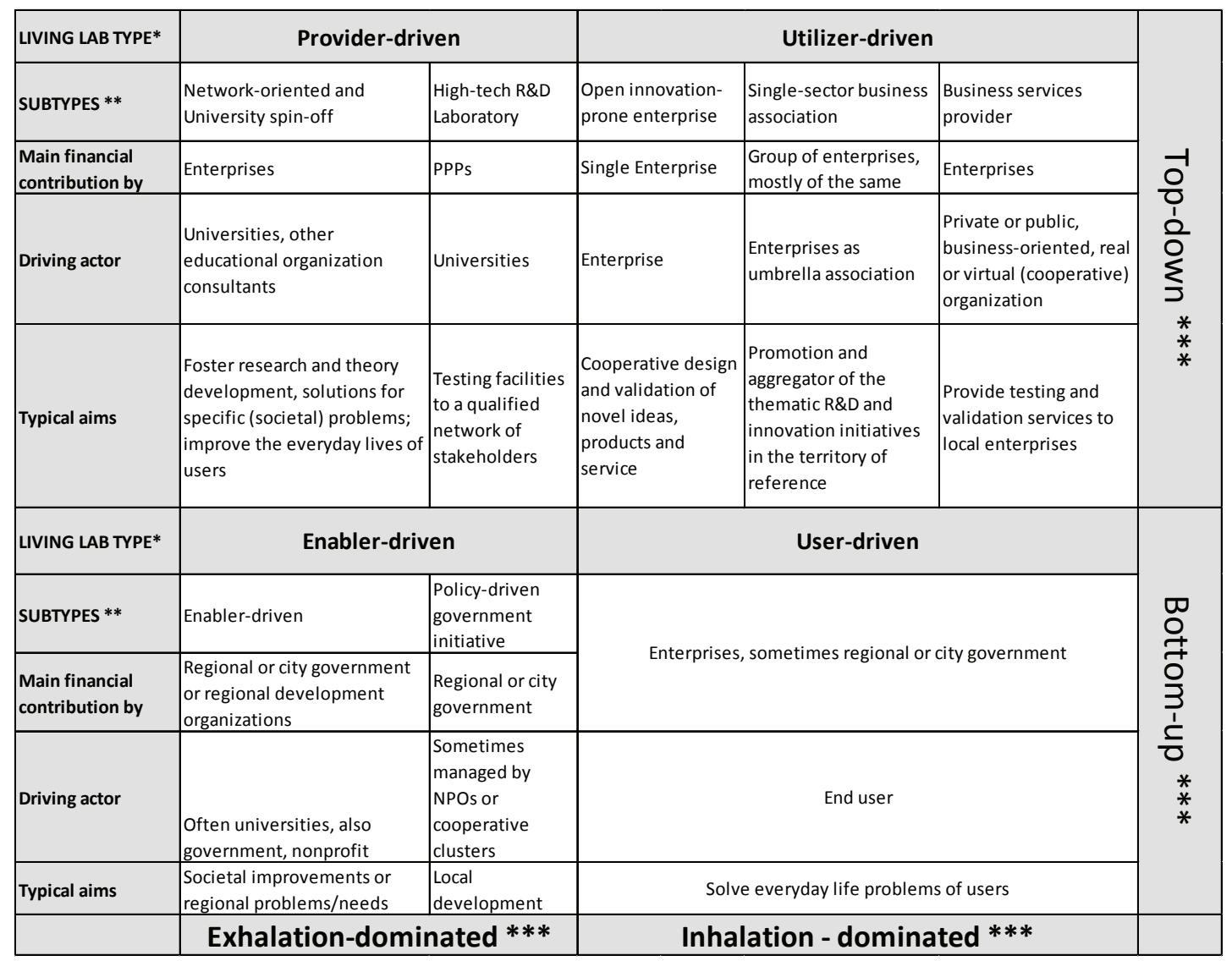

Two different types of mainly university-driven Living Labs form the group "provider-driven": Either as a network-oriented university spinoff, they foster research and theory development, mainly financed by enterprises; or as a high-tech R\&D laboratory, financed by PPPs, their typical aim is to test facilities for a qualified network of stakeholders. Those Living Lab types rather follow top-down structures, just as does the group of utilizer-driven Living Labs. Utilizer-driven Living Labs are typically financed and driven by a single enterprise or groups of enterprises or private or public, business-oriented organizations and are rather inhalation-dominated, meaning the needs of a driving party are fulfilled by engaging outside stakeholders in an innovation process (Leminen, 2013). The group of user-driven Living Labs, driven by end users to solve everyday life problems, can also be considered inhalation-dominated, but definitely as a bottom-up process. The fourth group, the enabler-driven Living Labs, is mostly financed by regional or city governments or development organizations in order to foster regional development and improvements, and can be divided into two types: The "policy-driven government initiative," often managed by Nonprofit Organizations or cooperative clusters, and the one often driven by universities. Both are rather bottom-up initiatives and exhalation-dominated, inviting parties to offer their knowledge, expertise and resources to an open innovation network, whereby the latter compares to the participation approach of provider-driven Living Labs.

Based on the above literature review, the authors analyzed comparable existing Living Labs dealing with transportation issues all around the world by comparing their aims, structures, approaches and stakeholders. This led to a number of comparable Living Labs concerning structures and approaches, although none of them deals with industrial mobility in the way it is defined here. The industrial mobility Living Lab for the region of Upper Austria proposed in this article can best be captured through the following structure: As the aim of the Living Lab is to develop solutions for a multisectorial, multilevel topic and for a whole region, neither single organizations nor certain users should be the drivers, nor certain technologies (and thus businesses) will be in favor. It seems most appropriate to develop a Living Lab driven by a higher-education organization, willing and

2) according to Leminen, S., Westerlund, M., \& Nyström, A.-G. (2012). Living Labs as open-innovation networks. Technology Innovation Management Review, September 2012, pp. 5-11.

3) according to Alcotra Innovation Project (2011). Deliverable 2.3. Best practices database for Living Labs: Overview of the Living Lab approach -Living Lab Best Practice Database Specification.

4) according to Leminen, S. (2013). Coordination and participation in Living Lab networks. Technology Innovation Management Review, November 2013, pp.4-14. 
able to collect requests from all stakeholder groups as well as to act as a moderator and intermediary between the public and private sector in order to foster co-creation. According to table 1, the Living Lab type would rather be an "enabler-driven" one, but with the strong aim of including the business sector such as industry, logistics suppliers, alternative transportation providers etc. equally, right from the beginning. Concerning public participation, the industrial mobility Living Lab would thus provide stability through a top-down structure, but with the strong aim of opening up to any bottom-up initiatives.

As a next step the research team addresses the whole innovation part of a Living Lab as this also represents the services offered by the implemented structure. Within the harmonization cube this task is presented by the parts user involvement, service creation, innovation outcomes and methods \& tools. The last part (methods \& tools) is seen as the most relevant part as it determines all the other aspects. If a Living Lab applies a good methodology with effective tools the user involvement as a core part for co-creating solutions in a systemic way (method) creates services, products and know-how. Also included here are the technologies required in order to perform measurements and analyze collected data.

\section{Part 3) Living Lab - creating an innovative environment}

Within this section, we will go into the theory of innovation. From the first step (orientation part) the strategic topic "Mobility as a Service" was identified as the main topic. Therefore, we start by looking at the innovation process from a service-oriented perspective (see harmonization cube "service creation). Mobility as a Service (MaaS) describes a mobility distribution model in which a customer's transportation needs are met over one interface. This is done within one bundled package. The system typically contains information about transport infrastructure, transportation and payment services. Mobility as a Service is seen as a new approach as the transport performance of the system is not evaluated primarily on speed, convenience and affordability. The new purpose will no longer be to improve the transport system by doing more or building more capacity, but by doing things in a smarter way (Hietanen, 2014). Therefore, mobility providers should focus on influencing factors addressing the innovation success of their services:

- Time-to-market speed at which innovations are introduced,

- The competition intensity and

- The availability and accessibility of information (Klokgieters \& Chu, 2013).

Thus, the MaaS-paradigm strongly shapes the usage of Information and Communication Technologies (ICT) in order to link the mentioned factors (harmonization cube "infrastructure"). ICT solutions are seen as main drivers in the service economy. Technology is changing the way services are characterized due to their consumption as well as production (Maffei, di Milano, Mager, \& Sangiorgi, 2005). Next to the high level of technical support, MaaS should also address the transformation to the so-called "supplier-user interface." The innovation theories highlight the fact that the underlying processes no longer take place within the boundaries of a single organization. They now involve complex relationships among several players, both private and public, some of which are competitive, while others are collaborative (Gabison and Pesole, 2014). The harmonization cube considers one specific stream of Gabison's research as relevant for innovation processes that focus on the role of external knowledge led by users:

- Open User Innovation (von Hippel, 2005): “economically important innovations are developed by users and other agents who divide up the tasks and cost of innovation development and then freely reveal their results."

The customer-oriented perspective has especially facilitated new methods of innovations. They are characterized by a more designdriven approach that is oriented toward generating new service ideas or products, through the use of technology potentials or the interpretation and proposal of new models of behavior (Maffei et al., 2005). Service design methods are both an evolution of existing marketing, management and design tools and the result of a dedicated design approach. The main and distinctive focus of service design tools concerns the design, description and visualization of the user experience, including the potentials of different interaction modes, paths and choices (flow diagrams, storyboarding, use cases, customer journey, video sketching, video prototyping, dramaturgy, etc.). Other tools try to support the representation of the complexity of service organization, like blueprint, service ecology, service system map, social network mapping, etc. (Maffei et al., 2005). Due to the definition of the underlying Living Lab, the service design approach is also appropriate for the case in question, Mobility Lab Upper Austria. The areas in which innovation can take place can be divided into three categories.

- Real-life context: social setting that involves stakeholders within the several innovation steps directly on site, where the action takes place.

- Virtual-life context: e-participation possibilities via online platforms or other (technical) supporting systems.

- Laboratory context: physical place where stakeholders can get together and experience actions within a neutral setting.

Figure 2: Service innovation process within a Living Lab setting.

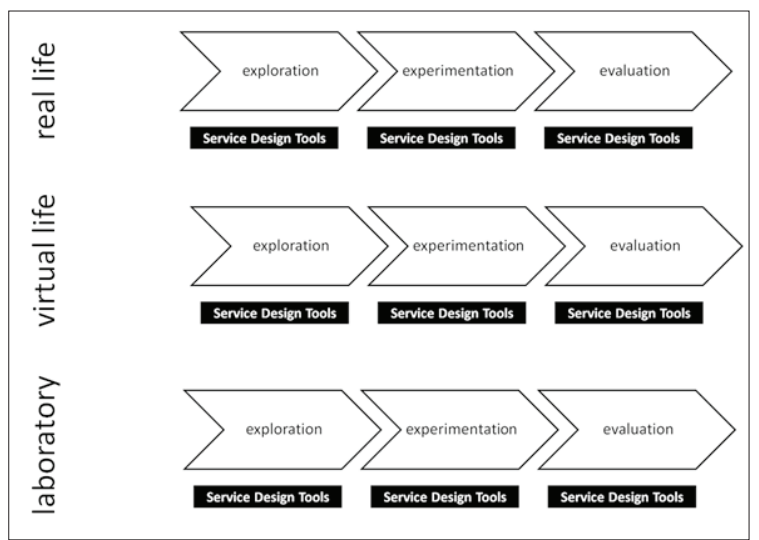




\section{Conclusion}

In order to link the single parts (1-3) into a conceptual picture, the following figure gives a first idea of how to align Living Labs on a theoretical level. This is also the construct of the "Mobi-Lab" in Upper Austria.

Figure 3: Mobi-Lab construction

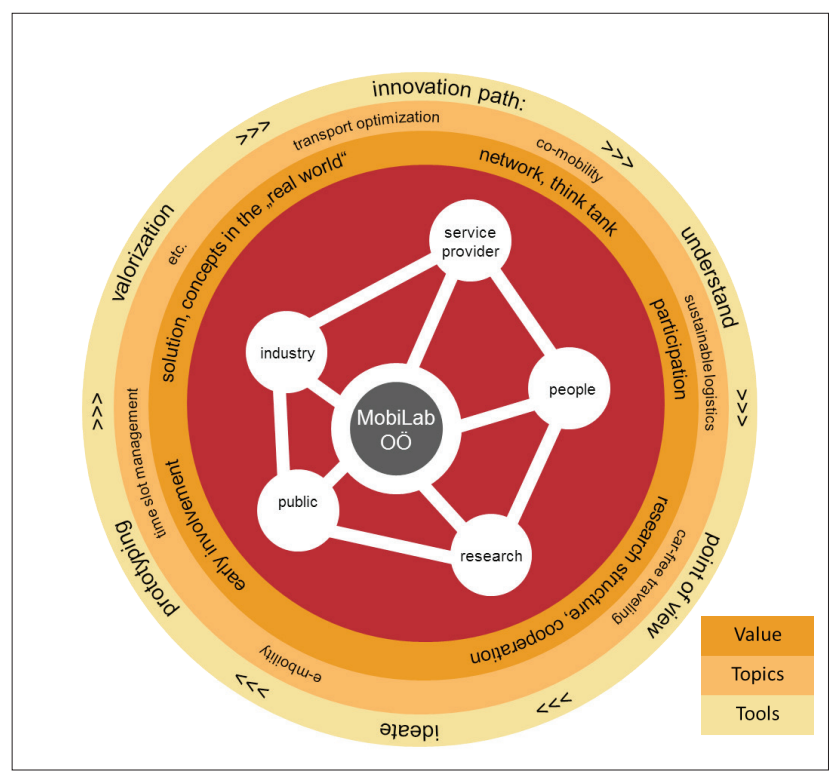

The inner circle represents the strategic orientation part by focusing on stakeholder integration. Within the research team, this part is seen as the most crucial task for the future. In particular, the group "people" will be defined as a rather small group of persons in their roles as employees or workers coming from or going to work, employees of logistics providers, and persons affected by particular traffic situations. Future research needs to be done in order to analyze different motivation/participation strategies. Therefore, values for stakeholders are mentioned (second inner circle) to point out clearly the advantages of using a Living Lab structure for future cooperation. This circle can be seen as a short summary of advantages in the Living Lab research also relevant for the value creation part within the business model part:

- Enabler for participation (from the business perspective)

- New research (infra-) structure

- Early involvement of (end-) users

- Innovative solutions within a real-world context

- Creation of a sustainable network/think tank

- Trial and error is allowed
The third circle demonstrates the topics identified during the stakeholder workshops already held. The linkage of passenger and freight transport solutions is especially seen as a big challenge for future research. All these parts need to be organized in an innovative way. Therefore, the outer circle represents an innovation process. Through the integration of relevant stakeholders in every single step, new and innovative solutions should be developed. To analyze the mechanism behind the Living Lab additional research will be done in the future. The measurement of innovation and participation tools is required to evaluate the impact of the Living Lab structure compared to classic project settings used.

\section{Acknowledgment}

The region of Upper Austria is used as a research case in order to demonstrate results and findings of an applied research project, called "Industriemobilitätslabor Zentralraum OÖ" (IMOLA). This project is supported by the Austrian national research promotion agency (FFG) in the program "mobility of the future."

\section{References}

Alcotra Innovation Project (2011). Deliverable 2.3. Best practices database for Living Labs: Overview of the Living Lab approach -Living Lab Best Practice Database Specification, Available from: http://www. alcotra-innovation.eu/progetto/doc/Best.pdf.

ENoLL, 2006. What is a Living Lab? Available from: http://www. openLivingLabs.eu/aboutus.

Gabison, G., \& Pesole, A. (2014). Open innovation, user innovation and social innovation. In: Joint Research Centre, European Commission, Institute for Prospective Technological Studies.

Gibbert, M., Ruigrok, W., \& Wicki, B. (2008). What passes as a rigorous case study? Strategic Management Journal, 29, pp. 1465-1474.

Hietanen, S. (2014). Mobility as a service: The new transport model? Eurostransport Magazine, 12(2), 1-3.

Klokgieters, K., \& Chu, R. (2013). Creating an environment for successful innovation: A management consultant's perspective. In: Evolution of innovation management: Trends in an international context, pp. 327-347.

Leminen, S. (2013). Coordination and participation in Living Lab networks. Technology Innovation Management Review, November 2013, pp.4-14.

Leminen, S., Westerlund, M., \& Nyström, A.-G. (2012). Living Labs as open-innovation networks. Technology Innovation Management Review, pp. 5-11.

Maani, K., \& Cavana, R. Y. (2007). Systems thinking, system dynamics. Managing change and complexity. 2nd ed. North Shore, N.Z.: Pearson Education New Zealand. 
Maffei, S., di Milano, P., Mager, P., \& Sangiorgi, D. (2005). Innovation through service design. From research and theory to a network of practice. A users' driven perspective. University of Art and Design Helsinki, pp. 22-24, Available from: http://www2.uiah.fi/joiningforces/papers/ Maffei_et_al.pdf.

Mastelic, J., Sahakian, M., \& Bonazzi, R. (2015). How to keep a Living Lab alive?, info, 17(4), pp. 12-25, http://dx.doi.org/10.1108/info-012015-0012.

Mulder, I., Velthausz, D., \& Kriens, M. (2008). The Living Lab harmonization cube: Communicating Living Labs' essentials. The Electronic Journal for Virtual Organizations and Networks, 10, pp. 1-14.
Nguyen, N. C., Bosch, O., \& Maani, K. (2011). Creating 'learning laboratories' for sustainable development in biospheres: A systems thinking approach. Systems Research and Behavioral Science, 28(1), pp.51-62.

Veeckman, C., Schuurman, D., Leminen, S., \& Westerlund, M. (2013). Linking Living Lab characteristics and their outcomes: Towards a conceptual framework. Technology Innovation Management Review, 3(12), 6-15.

Von Hippel, E. (2005). Democratizing innovation. Cambridge: The MIT Press. 